\title{
Developing standardized methods for breeding preharvest sprouting resistant wheat, challenges and successes in Canadian wheat
}

\author{
R. M. DePauw $\cdot$ R. E. Knox $\cdot$ A. K. Singh $•$ \\ S. L. Fox $\cdot$ D. G. Humphreys $\cdot$ P. Hucl
}

Received: 25 July 2011/Accepted: 23 December 2011/Published online: 3 February 2012

(C) The Author(s) 2012. This article is published with open access at Springerlink.com

\begin{abstract}
Preharvest sprouting (PHS) in spring wheat (Triticum aestivum L.) and durum wheat ( $T$. turgidum L. var durum) causes significant economic losses due to a reduction in grain yield, grain functionality and viability of seed for planting. Average annual estimated losses in Canada are about $\$ 100$ million. Genetic resistance to PHS reduces these losses. Development of PHS resistant cultivars is complicated by the effects of factors under genetic control, such as spike morphology, seed dormancy, environment, and kernel diseases. Resistance to PHS has been a breeding priority since the late 1960s. Development of RL4137, which is the primary source of PHS resistance in the Canada Western Red Spring market class, has led to cultivar improvements. A white-seeded derivative of RL4137 is the primary source of PHS in the Canada Prairie Spring White and Canada Western Hard White Spring wheat market
\end{abstract}

R. M. DePauw $(\varangle) \cdot$ R. E. Knox · A. K. Singh

Semiarid Prairie Agricultural Research Centre,

Agriculture and Agri-Food Canada, P. O. Box 1030,

Swift Current, SK S9H 3X2, Canada

e-mail: ron.depauw@agr.gc.ca

S. L. Fox · D. G. Humphreys

Cereal Research Centre, Agriculture and Agri-Food

Canada, 195 Dafoe Rd, Winnipeg, MB R3T 2M9, Canada

P. Hucl

Crop Development Centre, Plant Sciences, University of Saskatchewan, 51 Campus Drive, Saskatoon,

SK S7N 5A8, Canada classes. Procedures to select for PHS resistance vary among breeding programs, market classes and by degree of inbreeding. Methods include artificial sprouting of intact spikes, germination tests, natural weathering in field trials, artificial weathering trials, and indirect assessment of sprouting by measuring Hagberg falling number. Although many genetic loci have been attributed to preharvest sprouting resistance, application of molecular markers is currently limited due to the complex inheritance of the trait. In Canada, cultivars are characterized for their relative level of PHS resistance and the information is made available to producers.

Keywords Dormancy · Pre-harvest sprouting · Genetic resistance $\cdot$ Breeding methods - Triticum

\section{Introduction}

Germination of wheat (Triticum spp.) kernels, including initiation of germination and the induction of alpha-amylase without any visible evidence of embryo growth, causes significant economic losses in grain yield, grain functionality and viability of seed for planting (Derera 1989). In Canada, losses amounting to several hundred millions of dollars are experienced due to reduction in market grade in about three out of ten years (Derera 1989; Clarke et al. 2005). Economic losses due to preharvest sprouting (PHS) can be reduced by developing cultivars with increased 
dormancy and preharvest sprouting resistance (Czarnecki et al. 1986; McCaig and DePauw 1992) and by direct harvesting procedures (Clarke et al. 1984).

Procedures used to study and or incorporate genetic resistance differ by science project objectives and by breeding objectives. Various methods have been developed to measure seed dormancy and to assess preharvest sprouting tolerance (Derera 1989). DePauw and McCaig (1991) compared various assays that measure sprouting tolerance, seed dormancy, and alpha-amylase activity. The phenotypic correlations among the various assays were significant and positive. Genotypic effects accounted for $44-90 \%$ of the phenotypic variation. Heritability expressed on a genotype mean basis ranged from 0.59 to 0.93 and was highly significant. In genetic analyses and cultivar development procedures, it is important to measure a trait such that it minimizes the error variation relative to the genetic variation. Because preharvest sprouting tolerance is only one trait of a very large suite of traits to be integrated into a cultivar, the methods used in cultivar development have to be moderately to highly heritable, reliable and yet low cost, especially in the early generations.

Canadian wheat is segregated into market classes based on end-use suitability parameters of grain protein concentration, gluten strength, and kernel color (DePauw and Hunt 2001) (Table 1). Producers choose to grow cultivars of a market class based on

Table 1 Percentage of total wheat area seeded to market classes of spring and winter hexaploid wheat and durum wheat in Canada from 2005 to 2010

\begin{tabular}{lc}
\hline Wheat market class $^{\mathrm{a}}$ & $2005-2010^{\mathrm{b}}$ \\
\hline Canada Western Red Spring (CWRS) & 64.8 \\
Canada Western Amber Durum (CWAD) & 21.9 \\
Canada Western Red Winter (CWRW) & 4.0 \\
Canada Prairie Spring Red (CPSR) & 2.3 \\
Canada Western Soft White Spring (CWSWS) & 1.1 \\
Canada Western Hard White Spring (CWHWS) & 1.7 \\
Canada Prairie Spring White (CPSW) & 0.2 \\
Canada Western Extra Strong (CWES) & 0.1 \\
Canada Western General Purpose (CWGP) & 0.1 \\
Canada Eastern Winter Wheat & 3.8 \\
Total & 100.0 \\
\hline
\end{tabular}

a Details of market classes is in DePauw and Hunt (2001)

b Adapted from: M. Grenier Canadian Wheat Board economic considerations, market opportunities, and cultivar response to local abiotic and biotic stresses. Breeding programs target release of cultivars to meet the agronomic performance, resistance to biotic factors, and the necessary quality attributes that define each market class.

This paper reviews the breeding methods employed by Canadian breeders to incorporated genetic resistance to preharvest sprouting in various wheat market classes. This information can serve as a guide to future Canadian breeders and to breeders establishing programs in other nations.

\section{Methods for selection of preharvest sprouting resistance used at Cereal Research Centre}

The methods used to incorporate PHS resistance, at Cereal Research Centre Agriculture and Agri-Food Canada, Winnipeg, to meet cultivar registration requirements are similar for the Canada Western Red Spring (CWRS) and Canada Western Hard White Spring (CWHWS) market classes. Crosses aim to include at least one parent that has a high level of PHS resistance (i.e. AC Domain, AC Majestic, Harvest, Snowbird, Snowstar or derivative genotype Table 2). All of these parents are derivatives of RL4137 which has a proven high level of dormancy (DePauw et al. 2009). DePauw and McCaig (1983) provided evidence that RL4137 has two mechanisms for dormancy: one associated with red seed coat color and another mechanism independent of seed coat color. For crosses with parentage that suggests PHS resistance is likely inadequate, $F_{2}$ spikes are selected without stratification for maturity and stored at $-20^{\circ} \mathrm{C}$ until phenotyping. The $\mathrm{F}_{2}$ spikes are subjected to a wetting treatment in a rain simulator and only those spikes with no sprouted seeds are selected, threshed, and kernels examined. The $\mathrm{F}_{2}$ spike- $\mathrm{F}_{3}$ progeny are grown out in greenhouses over the winter months so that thorough screening is conducted and not rushed to make contra-season nursery seeding dates.

Per population, 400 to $500 \mathrm{~F}_{2}$ spikes (Table 3) are exposed to 3-5 days of artificial weathering. Spikes are rated for evidence of visible germination: spikes with more than two seeds germinated (visible coleoptile or roots) are discarded. The remaining spikes are dried, threshed, and seed rated for appearance: seed rated "good" generally has no visible sprouting; 
Table 2 Examples of cultivars with preharvest sprouting resistance, parentage, and market class

\begin{tabular}{|c|c|c|c|c|}
\hline Name & Parentage & Class $^{\mathrm{a}}$ & Reference & Source PHS \\
\hline Columbus & Neepawa*6/RL4137 & CWRS & $\begin{array}{l}\text { Campbell and Czarnecki } \\
1981\end{array}$ & RL4137_derivative \\
\hline $\begin{array}{l}\text { AC } \\
\text { Domain }\end{array}$ & ND499/RL4137//ND585 & CWRS & $\begin{array}{l}\text { Townley-Smith and } \\
\text { Czarnecki } 2008\end{array}$ & RL4137_derivative \\
\hline Pasqua & BW63*2/Columbus & CWRS & Townley-Smith et al. 1993 & RL4137_derivative \\
\hline AC Vista & HY344/Losprout 'S'//HY358*3/Bt10 & CPS_white & DePauw et al. 1998 & W_RL4137 \\
\hline $\begin{array}{l}\mathrm{AC} \\
\text { Majestic }^{\mathrm{c}}\end{array}$ & $\begin{array}{l}\text { Columbus*2//Saric 70/Neepawa/3/Columbus*5// } \\
\text { Saric 70/Neepawa }\end{array}$ & CWRS & $\begin{array}{l}\text { Townley-Smith and } \\
\text { Czarnecki } 1995\end{array}$ & RL4137_derivative \\
\hline Waskada & $\begin{array}{l}\text { AC_Domain*2/Sumai_3//2*Superb } \\
\quad(\text { Superb }=\text { Grandin*2/AC Domain })\end{array}$ & CWRS & Fox et al. 2009 & RL4137_derivative \\
\hline Harvest & AC Domain*2/ND 640 & CWRS & Fox et al. 2010 & RL4137_derivative \\
\hline Snowbird & RL4137*6//Thatcher/Poso48/3/AC Domain & CWHWS & Humphreys et al. 2007 & W_RL4137 \\
\hline Snowstar & 94B46*G22/McKenzie & CWHWS & DePauw et al. 2006 & W_RL4137 \\
\hline
\end{tabular}

${ }^{a}$ CWRS is Canada Western Hard Red Spring. CPS_white is Canada Prairie Spring_White. CWHWS is Canada Western Hard White Spring

b White seeded derivative of RL4137 as a source of preharvest sprouting resistance

c AC Majestic tested as BW173

Table 3 Summary of response of $F_{2}$ intact spikes using an artificial rain simulator to identify preharvest sprouting resistant lines

\begin{tabular}{|c|c|c|c|c|c|}
\hline \multirow[t]{2}{*}{ Cross } & \multirow[t]{2}{*}{ Parentage } & \multirow[t]{2}{*}{ Year } & \multicolumn{3}{|l|}{ Spikes } \\
\hline & & & \# 'good’ & Total & $\begin{array}{l}\% \text { rated } \\
\text { 'good' }\end{array}$ \\
\hline BG30 & BA83-EC-8/BW841 & 2008 & 89 & 434 & 21 \\
\hline BG33 & 99B26-AK3B/BW391 & 2008 & 65 & 407 & 16 \\
\hline BG48 & $\mathrm{BB} 07 \mathrm{~A} * \mathrm{~A} 637 / \mathrm{BW} 342$ & 2008 & 33 & 385 & 9 \\
\hline BG51 & BA21-CM-9/BW342 & 2008 & 97 & 408 & 24 \\
\hline BG57 & 99B28-EK4F/BA21-CD-20 & 2008 & 53 & 414 & 13 \\
\hline ВH03 & ND739/BW431//BW342 & 2009 & 143 & 507 & 28 \\
\hline BH07 & BW415/BW342 & 2009 & 156 & 501 & 31 \\
\hline BH20 & SD3948/BW430 & 2009 & 171 & 500 & 34 \\
\hline $\mathrm{BH} 32+\mathrm{BH} 33$ & $\mathrm{~K} 2619=\mathrm{HF} 15^{*} \mathrm{~A} 0084 / \mathrm{K} 2626 \& 2628$ & 2009 & 217 & 500 & 43 \\
\hline BJ11 & ACS 54608/Waskada & 2010 & 30 & 512 & 6 \\
\hline BJ19 & $3 \times 1-134 * F A 0067 / B W 357$ & 2010 & 69 & 550 & 13 \\
\hline $\mathrm{BJ} 25$ & ND04/3-21/BW874 & 2010 & 44 & 561 & 8 \\
\hline BJ05 & HW341/Waskada & 2010 & 69 & 511 & 14 \\
\hline
\end{tabular}

"fair" seed is somewhat shriveled with little or no visible sprouting; "poor" seed is shriveled with many seeds sprouted. Seed shriveling may be due to seed pathogens which may have a tendency to reduce dormancy (Fox et al. 2003). The CWRS cultivars AC Majestic, AC Domain and Harvest all derive from $\mathrm{F}_{2}$ populations that were subjected to artificial weathering and have parentage related to RL4137 (Table 2).
Stage two testing involves collection of spikes from single row plots $5 \mathrm{~m}$ long of $\mathrm{F}_{9}$ and $\mathrm{F}_{10}$ lines, and entries into pre-registration and registration trials. Stratification for maturity is achieved by sampling spikes from a plot when the majority of the ultimate stem nodes have turned brown and collapsed. Spikes are air dried for 2 days prior to storage at $-20^{\circ} \mathrm{C}$ until phenotyping. All lines are evaluated for sprouting 
scores on a 1-9 scale (Rasul et al. 2009). $\mathrm{F}_{10}$ lines and entries into pre-registration and registration trials are also evaluated for Hagberg falling number using artificial weathering as described by Rasul et al. (2009). Lines that demonstrate poor PHS resistance relative to standard cultivars are dropped from further testing.

\section{Methods for selection of preharvest sprouting resistance used at SemiArid Prairie Agricultural Research Centre (SPARC)}

At SPARC, Agriculture and Agri-Food Canada, Swift Current, similar methods are used to incorporate PHS resistance to meet cultivar registration requirements in CWRS, CWHWS, and Canada Western Amber Durum (CWAD) market classes. Crosses are planned with at least one parent that has a high level of PHS resistance. To ensure dormancy genes are not lost unintentionally from the non-germination of dormant seed during rapid generation advancement or use of contra season nurseries, dormancy breaking methods are applied to the seed such as hydrogen peroxide $\left(10 \mathrm{~g}^{-1}\right)$, potassium nitrate $\left(2 \mathrm{~g} \mathrm{l}^{-1}\right)$, gibberellic acid $\left(0.1 \mathrm{~g} \mathrm{l}^{-1}\right)$, heat treatment, scarification, and or temperature cycling (DePauw and Clarke 1976; Matus-Cádiz and Hucl 2003). The rigor of testing increases as lines advance through the breeding program with three stages of testing.

In the first stage to characterize early generation breeding lines for preharvest sprouting response in targeted populations, a sprouting index is determined based on both the number of spikes out of a ten spike sample with visible evidence of sprouting and on the intensity of the sprouting (DePauw et al. 2009). Each population is stratified for maturity by collecting a sample of 10 spikes when the ultimate stem node collapse and turn brown (equivalent to about $16 \%$ moisture on a wet weight base), air dried for $24 \mathrm{~h}$, and stored at $-20^{\circ} \mathrm{C}$ until phenotyping. The ten spikes are bound tightly into a bundle by a waterresistant sticky label upon which the appropriate experimental unit information is printed. The response to sprouting of intact spikes is assayed by subjecting the ten-spike bundles to a uniform wetting treatment in a rain simulation chamber. The ten-spike bundles are placed upright on a tray fitted with wire mesh on a $0.5 \mathrm{~cm}$ grid. An initial wetting treatment of about $135 \mathrm{~mm}$ in $5 \mathrm{~h}$ is followed by $1 / 2 \mathrm{~h}$ misting every $12 \mathrm{~h}$. Temperature is maintained at $18^{\circ} \mathrm{C}$ and relative humidity greater than $95 \%$. If a population is segregating for seed coat color, the experimental lines are classified for seed color using a sodium hydroxide test (DePauw and McCaig 1988). Selection is based on sprouting index within groups based on seed color. A selection cut-off is established relative to the sprouting index of a set of check cultivars with known response. Selection for preharvest sprouting response is performed on the $F_{4}$ and $F_{6}$ breeding lines in conjunction with selection for a multitude of diseases, agronomic response traits, and end-use quality. A typical starting population of about 10,000 single $F_{2}$ plants per cross rapidly declines until either nothing remains or an experimental line meets sprouting resistance criteria of check cultivars and all criteria to be registered as a cultivar such as AC Vista (Table 2).

Stage two testing is more detailed than stage one and involves an assessment of the length of the dormancy period by using two sampling periods about 10 days apart as well as two or more replications (DePauw et al. 2009). The protocol involves stratifying for maturity and collecting a sample of ten spikes as described above. Following the artificial rain simulation treatment and scoring for number of heads with visible evidence of sprouting, the samples are dried down, threshed and percentage of kernels sprouted is determined following the methods described by DePauw et al. (2009).

Stage three testing is performed on experimental lines in the final year of registration trials and recently registered cultivars. Stage three testing includes the two aforementioned treatments and provision for natural weathering without stratification for maturity (DePauw et al. 2009). In the natural weathering test, the initial harvest occurs when the latest maturing genotypes have attained about $16 \%$ moisture content on a wet weight basis. The second harvest date occurs after about $10 \mathrm{~mm}$ rainfall and within an interval of 10-25 days. The third harvest date involves similar criteria but before permanent snow cover. Variables measured on the natural weathered samples are Hagberg falling number, grain volume weight and polyphenyl oxidase. After 3 years of testing, the cultivars are classified for resistance to preharvest sprouting, and the information is made available producers and the public (e.g. http:// www.agriculture.gov.sk.ca/Varieties_Grain_Crops). 


\section{Methods for selection of preharvest sprouting resistance used at Crop Development Centre (CDC), University of Saskatchewan}

The CDC CWRS program has been selecting for pre-harvest sprouting tolerance since 1990. Parents with RL4137 in their background such as Columbus, Pasqua, AC Domain, and AC Majestic were used routinely in developing populations (Table 2). Progeny were selected on the basis of artificial sprouting of intact spikes in the $F_{5}$ or $F_{6}$ generation. Spikes were harvested from hills that had not been culled on the basis of leaf or stem rust reaction. Starting in the mid1990's, the CDC CWRS and CWHW program has set up a natural weathering nursery (single rows $1.3 \mathrm{~m}$ long per entry) which is typically seeded each year in early May. This nursery contains 1,500-2,000 entries which represent $F_{7}$ and $F_{8}$ lines in replicated yield trials. The entries are rated for shattering (and stem solidness if appropriate) and spikes are harvested in late October and stored in an un-heated facility. Lines that are advanced on the basis of agronomic performance, disease reaction and small-scale predictive quality tests are then subjected to a Hagberg falling number test. For a number of years weathered grain samples were objectively evaluated using the HunterLab L* and a* values (McCaig et al. 2006); however, lack of progress using the latter approach suggested that it was ineffective.

\section{Hagberg falling number and cultivar registration}

For an experimental line to be eligible for registration it must pass three consecutive years of assessment relative to up to five standard cultivars in the categories of agronomic performance, response to diseases and end-use quality. The Quality Evaluation Team of the Prairie Recommending Committee on Wheat, Rye and Triticale, uses five standard cultivars to represent the acceptable range of milling, rheological and baking properties based on input from domestic and international customers familiar with CWRS quality. The same principles hold true for other market classes. Each year the registration trials are grown at about 13 locations in replicated tests. A subsample of the yield trial grain from locations representative of the top two grades are composited and is intended to be representative of the geographical area and protein content of the crop-year. The composite is used as the basis for measuring the milling, rheological and baking properties of the checks and candidate cultivars.

Based on committee membership expertise and customer feedback on wheat class quality, a level of acceptability is established for each quality parameter. A mean of the checks is constructed for each quality parameter. Each check and candidate cultivar is scored as a deviation from the mean of the checks. Deviations above and below this target of acceptability results in five classes: excellent, improvement, equivalent, flag and poor. The ranges for the five categories for Hagberg falling number are presented in Table 4. Within the CWRS market class, Hagberg falling number is classified as an essential trait. Candidates rated poor are eliminated from further trialing regardless of their agronomic performance or disease resistance. A candidate that successfully undergoes 3 years of registration trialing are summarized and

Table 4 Hagberg falling number of the rating scale, five checks and six candidate cultivars rated for acceptability of Hagberg falling number score in the 2008 Central Bread Wheat registration trial based on a seed composite of 6 of the 11 test locations

\begin{tabular}{|c|c|c|c|c|}
\hline Genotype & & $\begin{array}{l}\text { Hagberg } \\
\text { falling } \\
\text { number } \\
\text { (s) }\end{array}$ & $\begin{array}{l}\text { Deviation } \\
\text { from mean } \\
\text { of checks } \\
\text { (s) }\end{array}$ & Rating \\
\hline & Scale & 520 & 79 & Excellent \\
\hline & Scale & 476 & 35 & Improvement \\
\hline \multirow{3}{*}{$\begin{array}{r}\text { Mean of } \\
\text { checks }\end{array}$} & Scale & 441 & 0 & Equivalent \\
\hline & Scale & 406 & -35 & Flag \\
\hline & Scale & 362 & -79 & Poor \\
\hline Katepwa & Check & 430 & -11 & Equivalent \\
\hline McKenzie & Check & 430 & -11 & Equivalent \\
\hline CDC Teal & Check & 435 & -6 & Equivalent \\
\hline Unity VB & Check & 450 & 9 & Equivalent \\
\hline $5603 \mathrm{HR}$ & Check & 460 & 19 & Equivalent \\
\hline BW 394 & 3rd year & 450 & 9 & Equivalent \\
\hline BW 424 & 1st year & 280 & -161 & Poor \\
\hline BW 428 & 1st year & 360 & -81 & Poor \\
\hline BW 429 & 1st year & 420 & -21 & Equivalent \\
\hline BW 432 & 1st year & 285 & -156 & Poor \\
\hline BW 433 & 1st year & 450 & 9 & Equivalent \\
\hline
\end{tabular}

Adapted from 2008 Central Bread Wheat Coop report Quality Evaluation Team, Prairie Recommending Committee Wheat, Rye and Triticale 
Table 5 Hagberg falling number and sprouting scores of BW429, and five checks cultivars from yield tests grown in 2008-2010

\begin{tabular}{|c|c|c|c|c|c|c|c|c|}
\hline \multirow[t]{2}{*}{ Cultivar } & \multicolumn{4}{|c|}{ Falling number on end-use suitability composites } & \multicolumn{4}{|c|}{ Falling number-natural weathering ${ }^{\mathrm{a}}$} \\
\hline & 2008 & 2009 & 2010 & Mean & 2008 & $2009^{b}$ & 2010 & Mean \\
\hline Katepwa & 430 & 435 & 370 & 412 & 253 & - & 238 & 246 \\
\hline McKenzie & 430 & 440 & 405 & 425 & 351 & - & 304 & 328 \\
\hline CDC Teal & 435 & 430 & 390 & 418 & 258 & - & 114 & 186 \\
\hline Unity VB & 450 & 475 & 435 & 453 & 378 & - & 386 & 382 \\
\hline $5603 \mathrm{HR}$ & 460 & 440 & 450 & 450 & 326 & - & 268 & 297 \\
\hline Mean & 441 & 444 & 410 & 432 & 313 & - & 262 & 288 \\
\hline BW429 & 420 & 430 & 395 & 415 & 312 & - & 330 & 321 \\
\hline $\mathrm{LSD}^{\mathrm{c}}$ & - & - & - & 29 & 56 & - & 106 & 107 \\
\hline \multirow[t]{2}{*}{ Cultivar } & \multicolumn{4}{|c|}{ Falling number-artificial weathering ${ }^{\mathrm{d}}$} & \multicolumn{4}{|c|}{ Preharvest sprouting score ${ }^{\mathrm{e}}$} \\
\hline & 2008 & 2009 & 2010 & Mean & 2008 & 2009 & 2010 & Mean \\
\hline Katepwa & 96 & 88 & 174 & 119 & 5.8 & 5 & 6.2 & 5.7 \\
\hline McKenzie & 198 & 172 & 261 & 210 & 2.1 & 6.3 & 3.7 & 4 \\
\hline CDC Teal & 73 & 72 & 104 & 83 & 6.4 & 6.6 & 6.8 & 6.6 \\
\hline Unity VB & 266 & 130 & 210 & 202 & 1.7 & 3.9 & 1.7 & 2.4 \\
\hline $5603 \mathrm{HR}$ & 248 & 217 & 303 & 256 & 1.9 & 3 & 1.4 & 2.1 \\
\hline Mean & 176 & 136 & 210 & 174 & 3.6 & 5 & 4 & 4.2 \\
\hline BW429 & 111 & 161 & 260 & 177 & 4.4 & 3.5 & 1.7 & 3.2 \\
\hline LSD & 114 & 84 & 74 & 70 & 2.0 & 1.7 & 2.4 & 2.1 \\
\hline
\end{tabular}

Quality composite samples were created from grain harvested from 6,10 and 8 locations for respective years of the Central Bread Wheat registration trial

a Field weathered samples are harvested when declines in falling number were observed for the sprouting susceptible cultivar Roblin

b Because there was insufficient precipitation to obtain a decline in falling number of Roblin, falling number was not measured on the other cultivars

c Least significant difference $P \leq 0.05$ for treatments, protected LSDs

d Collected at maturity, this material is placed in a rain simulator at $15^{\circ} \mathrm{C}$ for $48 \mathrm{~h}$, dried and then seed is ground into meal for falling number determination

e $((\#$ spikes with 0 sprouts $) \times 1+(\#$ spikes with 1 sprout $) \times 2+(\#$ spikes with 2 sprouts $) \times 3+(\#$ spikes with $3-5$ sprouts $) \times 5+(\#$ spikes with $>3$ sprouts $) \times 9) /$ total number of spikes evaluated. Spikes were collected at maturity and stored at $-20^{\circ} \mathrm{C}$ until they were evaluated. The mean was calculated over the 3 years of tests using SAS PROC MIXED procedure

presented to a panel of peers to determine if the candidate has merit for cultivation and use. As a recent example, Table 5 summarizes 3 years of measures of preharvest sprouting response for a recent successful candidate BW429. This protocol to evaluate candidates for registration has successfully minimized candidates which are susceptible to preharvest sprouting from being registered in western Canada.

\section{DNA molecular markers}

Characterization of dormancy and response to preharvest sprouting in mapping populations is used to determine inheritance and/or locate QTL's for the trait(s). A range of trait assessment methods have been used such as germination tests and sprouting index on intact spikes (Rasul et al. 2009; Knox et al. 2011). QTLs have been detected and published (Rasul et al. 2009; Knox et al. 2011) and haplotypes have been defined (Ogbonnaya et al. 2007; Fofana et al. 2009). Validation of QTL markers for preharvest sprouting resistance is challenging because of the large effort in phenotyping that is required to confirm desirable alleles are present in the most elite sources of resistance that are preferred as parents. Recently, the CDC hexaploid wheat breeding has been using a molecular marker developed by Singh et al. (2010). 
The first two advanced breeding lines from an effort to pyramid $L r 22 a$ with a major dormancy QTL on chromosome $4 A$ in a CDC Go (Hucl 2003) plant type were grown in the 2010 Parkland B pre-registration test for very short season northern areas. One of the lines (W09130) was the highest yielding entry in the trial, but was not advanced due to low loaf volume and undesirable FHB score. Currently at CDC, gametic selection in the $\mathrm{F}_{1}$ is being conducted to backcross the 4A QTL into CDC Go (backcross 7) as well as selecting parental material for population development. Resources permitting, this may lead to routinely genotype lines in the $\mathrm{F}_{6}$ and $\mathrm{F}_{7}$ for both the CWRS and CWHW classes. Generally, dissection of QTL's is required to develop molecular markers suitable for marker assisted breeding purposes.

\section{Conclusions}

Cultivars with moderate to high levels of preharvest sprouting resistance based on dormancy primarily from RL4137 have been released in the CWRS market class. White seeded cultivars have been released based on dormancy derived from RL4137, using the dormancy mechanism independent of seed coat color. Snowbird and Snowstar, hard white wheat varieties have high levels for PHS resistance comparable to some cultivars with red seed coat color. Screening protocols generally permit selection for high levels of PHS resistance without unacceptable reduction in population variance for other important traits. Bringing in new genes from non-adapted germplasm for agronomically desirable traits such as high grain yield potential or resistance to diseases such as Fusarium head blight while retaining CWRS or CWHWS or CWAD level of PHS resistance continues to be challenging. It is an on-going challenge to identify molecular markers for PHS that are applicable in a breeding program which requires markers to have little linkage drag, relevance across a diversity of genetic backgrounds, low cost and transferable to various laboratories.

Acknowledgments We gratefully acknowledge the financial support from the producer levy on wheat administered by the Western Grains Research Foundation, and the support staff at the Cereal Research Centre, SemiArid Prairie Agricultural Research Centre, and the Crop Development Centre that diligently implement the experimental protocols.
Open Access This article is distributed under the terms of the Creative Commons Attribution License which permits any use, distribution, and reproduction in any medium, provided the original author(s) and the source are credited.

\section{References}

Campbell AB, Czarnecki E (1981) Columbus hard red spring wheat. Can J Plant Sci 61:147-148

Clarke JM, Christensen JV, DePauw RM (1984) Effect of weathering on falling numbers of standing and windrowed wheat. Can J Plant Sci 64:457-463

Clarke FR, Clarke JM, DePauw RM, Fernandez MR, Fox S, Gilbert J, Humphreys G, Knox RE, McCaig TN, Procunier D, Sissons M, Somers D (2005) Strategic approach to mitigating weather induced defects of wheat quality. Euphytica 143:285-290

Czarnecki E (1986) Breeding and selecting for preharvest sprouting resistance in red wheats. In: Mares DJ (ed) Proceedings of 4th International Symposium on Pre-Harvest Sprouting in Cereals. Westview Press, Boulder, pp 45-53

DePauw RM, Clarke JM (1976) Acceleration of generation advancement in spring wheat. Euphytica 25:415-418

DePauw RM, Hunt LA (2001) Canadian Wheat Gene Pool. In: Bonjean AP and Angus WJ (eds) The world wheat book: a history of wheat breeding. Lavoisier Publishing, 11 rue Lavoisier, F-75384 Paris cedex 08, France, pp 479-515

DePauw RM, McCaig TN (1983) Recombining dormancy and white seed color in a spring wheat cross. Can J Plant Sci 63:581-589

DePauw RM, McCaig TN (1988) Utilization of sodium hydroxide to assess kernel color and its inheritance in eleven spring wheat varieties. Can J Plant Sci 68:323-329

DePauw RM, McCaig TN (1991) Components of variation, heritabilities and correlations for indices of sprouting tolerance and seed dormancy in Triticum spp. Euphytica 52:221-229

DePauw RM, McCaig TN, Knox RE, Clarke JM, Fernandez MR, McLeod JG (1998) AC Vista hard white spring wheat. Can J Plant Sci 78:617-620

DePauw RM, Clarke JM, Clarke FR (2006) Report on the hard white wheat cooperative test, 2005. In: Minutes of the Annual Meeting, Prairie Registration Recommending Committee for Grain: Wheat, Rye and Triticale Subcommittee Report, Banff, Alberta, pp 362-381

DePauw RM, Clarke FR, Fofana B, Knox R, Humphreys G, Cloutier S (2009) RL4137 contributes preharvest sprouting resistance to Canadian wheats. Euphytica 168:347-361

Derera NF (1989) Preharvest field sprouting in cereals. CRC Press, Boca Raton

Fofana B, Humphreys DG, Rasul G, Cloutier S, Woods SM, Brûlé-Babel AL, Lukow OM, Somers DJ (2009) Mapping quantitative trait loci controlling pre-harvest sprouting resistance in a red $\mathrm{x}$ white seeded spring wheat cross. Euphytica 1653:509-521. doi:10.1007/s10681-008-9766-6

Fox SL, Fernandez MR, DePauw RM (2003) Effect of red smudge infection and germination temperature on sprouting resistance in four wheat lines. Can J Plant Sci 83:163-169 
Fox SL, Thomas JB, Wise IL, Smith MAH, Humphreys DG, Brown PD, Townley-Smith TF, McCallum BD, Fetch TG, Menzies JG, Gilbert JA, Fernandez MR, Despins T, Niziol D (2009) Waskada hard red spring wheat. Can J Plant Sci 89:929-936

Fox SL, Townley-Smith TF, Thomas JB, Humphreys DG, Brown PD, McCallum BD, Fetch TG, Menzies JG, Gilbert JA, Fernandez MR, Gaudet DA, Noll JS (2010) Harvest hard red spring wheat. Can J Plant Sci 90:503-509

Hucl P (2003) CDC Go http://agbio.usask.ca/seed-form

Humphreys DG, Noll J (2002) Methods for characterization of preharvest sprouting resistance in a wheat breeding program. Euphytica 126:61-65

Humphreys DG, Townley-Smith TF, Czarnecki E, Lukow O, McCallum B, Fetch T, Gilbert J, Menzies J (2007) Snowbird hard white spring wheat. Can J Plant Sci 87:301-305

Knox RE, Clarke FR, Clarke JM, Fox SL, DePauw RM, Singh AK (2011) Enhancing the identification of genetic loci and transgressive segregants for preharvest sprouting resistance in a durum wheat population. Euphytica. doi: 10.1007/s10681-011-0557-0

Matus-Cádiz MA, Hucl P (2003) Comparison of pre-treatments for inducing germination in highly dormant wheat genotypes. Can J Plant Sci 83:729-735

McCaig TN, DePauw RM (1992) Breeding for preharvest sprouting tolerance in white-seed-coat spring wheat. Crop Sci 32:19-23
McCaig TN, Gan YT, Clarke P, Clarke JM, DePauw RM (2006) Kernel color changes associated with field weathering of spring wheat. Can J Plant Sci 86:371-377

Ogbonnaya FC, Muhammad I, DePauw RM (2007) Haplotype diversity at pre-harvest sprouting QTL's in wheat. Genome 50:107-118

Rasul G, Humphreys DG, Brûlé-Babel AL, McCartney CA, Knox RE, DePauw RM, Somers DJ (2009) Mapping QTLs for pre-harvest sprouting traits in the spring wheat cross RL4452/AC Domain. Euphytica 168:363-378. doi: 10.1007/s10681-009-9934-3

Singh R, Matus-Cádiz M, Båga M, Hucl P, Chibbar RN (2010) Identification of genomic regions associated with seed dormancy in white-grained wheat. Euphytica 174:391-408

Townley-Smith TF, Czarnecki EM (1995) Report on the Western Bread Wheat Cooperative Test, 1994. In: Minutes, 6th Annual Meeting, Prairie Registration Recommending Committee for Grain, Saskatoon, Saskatchewan, pp 1-19

Townley-Smith TF, Czarnecki EM (2008) AC Domain hard red spring wheat. Can J Plant Sci 88:347-350

Townley-Smith TF, Czarnecki E, Campbell AB, Dyck PL, Samborski DJ (1993) Pasqua hard red spring wheat. Can J Plant Sci 73:1095-1098 